\title{
Influence of Domestic Violence on Girl-Child Academic Performance of Students in Itesiwaju Local Government Area, Oyo State, Nigeria
}

\section{Ifeoma P. Okafor}

Ph.D., Department of Social Sciences Education, University of Ilorin, Nigeria, ifeomapokafor@gmail.com

Domestic violence is a purposeful use of force or strength on a person within and outside the house which affects the person adversely or the society at large. Therefore, this study examined the influence of domestic violence among Senior Secondary School Girls in Itesiwaju Local Government Area of Oyo State. Ex-post facto research design was adopted. The population comprised all Senior Secondary School Students of Itesiwaju Local Government Oyo State while the target population was 1,280 of which 32 respondents were chosen from the 40 Senior Secondary Schools used for the study. Simple random sampling technique was used to select the schools while purposive sampling technique was used to select the respondents Stratified random sampling technique was used to select the respondents. Questionnaire on the Influence of Domestic Violence among Senior Secondary School Girls (IDVASSGQ) was used to gather information from the respondents. The instrument was subjected to validation and test re-test reliability of 0.74 was realized. Chi square was used to test the hypothesis at 0.05 level of significance. The findings revealed that the level of domestic violence on girl-child among secondary school students in Itesiwaju Local Government Area, Oyo State was high. Findings further revealed that there was a significant influence of domestic violence on girl-child academic performance. Based on the findings, it was recommended that there should be awareness on dangers of violence on girl-child generally. This will educate, sensitise and eradicate all especially the girl-child on the dangers of violence. This will assist students to cope with the social vices associated with the violence especially the girl-child. The society at large should take responsibility of reporting the suspected abuser to the child protection agency or police; this would reduce the rate of violence. Strict laws should be formulated to protect female children generally from domestic violence.

Keywords: domestic, violence, girl-child, academic performance, domestic violence

\section{INTRODUCTION}

Domestic violence in most cases happens at home and it can be seen as an act of inflicting assault to an intimate relation or a group or community that its outcome is injury, death, physical harm and deprivation. It can also be in form of threat or intimidation. The person may be a boy or a girl. It can equally affect the person's education especially the girl-child. Domestic violence does not recognize gender, culture, religion, age, education, social status or ethnicity. It can happen to anybody and can come in any form such as physical abuse, rape, child marriage, denial of women to work, or right to own property, right to choose her husband, access to education, girl-child trafficking, using girl-child as commercial sex worker, verbal assault, emotional abuse, spouse battering, sexual abuse, dowry related violence, marital rape, incest, female genital mutilation, social neglect, psychological trauma and various traditional practices harmful to any member of the family.

Citation: Okafor, I. P. (2020). Influence of Domestic Violence on Girl-Child Academic Performance of Students in Itesiwaju Local Government Area, Oyo State, Nigeria. Anatolian Journal of Education, 5(1), 119-124. https://doi.org/10.29333/aje.2020.5111a 
Domestic violence has been outlined by Amnesty International as most violent attacks on an individual or group of people or women. It can be physical, sexual and psychological violence in the family which involved battering, sexual abuse of female children in the household, dowry related violence, marital rape, female genital mutilation and other traditional practices harmful to any member of the household (Barns, 2010). It is the systematic abuse by a person in a relationship so that he or she may dominate the other especially the weaker sex. Besides death and injury, the definition also includes the myriads and often less obvious consequences of violent behaviour such as psychological harm, deprivation, society crises that compromise the well-being of individuals, families and communities (World Health Organisation, 2002); (Watt \& Zimmerman, 2002, Barn, 2010). The victims are usually women and children because they are vulnerable members of the society. It mostly occur in patrilineal culture because of the cultures, customs and traditions that exist in societies like this and Nigeria is inclusive. Gender inequality has made the women the weaker sex and in a male dominated society like Nigeria (Watt \& Zimmerman, 2002, Barn, 2010).

The perpetrators of this act always threatened to kill, mien or harm the victim. Most of these victims remain mute because of their relationship with the perpetrators (Kanchiputu \& Mzuzu, 2016). Women too are not void of domestic violence to men and children, were women are seen. A person can manifest violence behaviour by merely living or staying with the perpetrator and it can affect the child's behaviour, health and academic performance in school (Kanchiputu \& Mzuzu, 2016). Domestic violence is not peculiar to Nigeria alone but the world at large (Indermaur, 2001). Domestic violence can be seen as physical, sexual, psychological or financial violence that takes place within an intimate or family-type of relationship and that forms a pattern of coercive and controlling measure (Women's world, 2009).

Gender based violence is an age-long psycho-social issue deeply rooted in the dwindling concept of gender inequality which is a kind of structural violence within any social system. This type of violence is widely used as violence against women and it depicts gender inequality in which most violence is rooted and it is an age-old social problem (USAID, 2006; Akpan, 2005).

Cases of violence on Nigerian students have been on the increase recently especially that of the girlchild such as torture, kidnapping, shooting, sexual harassment, rape, corporal punishments and so on. In response to global violence, a global in-depth study of violence against children was commissioned by United Nations Secretary General as directed by the general assembly resolution 57/90 of 2002 to provide a global picture. The report provides information that various types of violence exist against children within the family, schools, alternative care institutions, detention facilities, places where children and adolescents work for communities. In the year 2002, WHO reported that 53,000 children were murdered worldwide. A survey from many countries showed that between 20-65 percent of school aged children reported to have been bullied verbally or physically. Furthermore, WHO (2002) estimated that 150 million girls and 73 million boys under 18 were sexually abused (Wopadovi, 2014; Mohammad 2005).

Generally speaking, in our world today, parents serve as a role model whose behaviour children imitate and if the parents demonstrate aggressive or violent behaviour either directly or indirectly towards them, the child definitely learns how to be aggressive or violent. Where this happened, the person may experience malfunctioning in health and decrease in productivity. This may in turn affect the child's academic performance and the society at large (Lawal \& Ishaq, 2010).

Domestic violence is in various types. The most commonly acknowledged forms are physical and sexual violence, threats and intimidation, emotional and social abuse and economic deprivation. Secondary school student girls seem to constitute the greater percentage of recipients of the adverse effect of violence. Lawal and Ishaq (2010) reported that $70 \%$ of adolescents that live in families with parental rancour reported violent delinquency compared to $30 \%$ of adolescents from household 
without this rancor. Secondary school students are saddled with the mind of acquiring knowledge which is multi-dimensional in nature examples are affective, cognitive and psychomotor, subject based, teacher and learner oriented and of course extra curricula as they grow up in the society. It is against this background that this study investigated the influence of domestic violence on girl-child academic performance in senior secondary schools in Itesiwaju Local Government Area of Oyo State, Nigeria.

Domestic violence is one of current social problems facing the society at large especially the girl-child in secondary school. Many researchers such as Njorge (2014) worked on Domestic violence on academic performance of public secondary schools: a case study of Muguja location, kiambu, county Post graduate diploma: Thesis in Education in the university of Nairobi, Mitchell (2012) also worked on Violence in the family, Gracier and Herrero (2007) researched on Perceived Neighbourhood social disorder and attitude toward reporting domestic violence against women. Researchers like Donald (2010) and (Berns) 2010 carried out a research on child, family, school, community: socialisation and support in London observed that children experience the same level of negative psychosocial outcomes as children who are directly physically abused. Some of these researches are foreign based while most of them are position papers. This present research is an empirical study and it is carried out in Oyo state. To the best of the researcher's knowledge, none of these researchers have studied the influence of domestic violence on girl-child academic performance in secondary school in Itesiwaju Local Government Area of Oyo State. Thus, this is the gap left by the previous researchers which this present study intends to fill.

This study sought answers to the following questions:

1. What is the level of prevalence of domestic violence on girl-child among Secondary School Students in Itesiwaju Local Government Area, Oyo State?

2. What is the level of academic performance of Secondary School in Itesiwaju Local Government Area, Oyo State?

\section{Hypothesis}

The following research hypothesis was formulated based on the research questions.

H0 $\mathbf{0}_{1}$ : There is no significant influence of domestic violence on Secondary School Students academic performance in Itesiwaju Local Government Area, Oyo State.

\section{METHOD}

The research design adopted for this study is ex-post facto research design since the researcher is interested in collecting information from a representative sample. The population of this study is all Senior Secondary School Students of Itesiwaju Local Government Oyo State but the target population was 1,280 of which 32 respondents were chosen from the 40 Senior Secondary Schools used for the study. Simple random sampling technique was used to select the schools while purposive sampling technique was used to select the respondents Purposive sampling is a kind of sampling method that enables the researcher to pick respondents based on convenience. A 20 items researcher-designed questionnaire on Influence of Domestic Violence among Senior Secondary School Girl-child was developed and tagged (IDVASSGQ) Section 'A' of the instrument formed the demographic data of the respondents while sections ' $B$ ' is patterned after the four point Likert type rating scale format of: Strongly Agree $(\mathrm{SA})=4$ points, Agree $(\mathrm{A})=3$ points, Disagree $(\mathrm{D})=2$ points and Strongly Disagree $(\mathrm{SD})=1$ point. The instrument was subjected to content validity by test and measurement experts in the Department of Social Sciences Education University of Ilorin. The reliability coefficient of 0.74 was realized. A proforma was used to collect data on the academic performance of the respondents.

The results obtained from the data were analysed with chi-square statistics and tested at 0.05 level of significance. 


\section{FINDINGS}

\section{Answering of Research Questions}

Two research questions were raised and answered in this study. Research question 1was answered using average mean score; research question 2 was answered using percentage.

Research Question 1: What is the level of domestic violence on girl-child among secondary schools students in Itesiwaju Local Government Area, Oyo State?

Table 1

Percentage Analysis of Prevalence of Domestic Violence on Academic Performance of Secondary School in Itesiwaju Local Government Area, Oyo State

\begin{tabular}{lll}
\hline Prevalence of Domestic Violence & Frequency & Percentage $(\%)$ \\
\hline High & 892 & 69.6 \\
Low & 388 & 30.4 \\
Total & 1280 & 100.0 \\
\hline
\end{tabular}

Table 1 presents the responses of the participants to items that sought information on the prevalence of domestic violence on academic performance of secondary school in Itesiwaju Local Government Area, Oyo State. The results indicated that 892 representing $(69.6 \%)$ of prevalence of domestic violence on academic performance was high, while 388 representing (30.4\%) of prevalence of domestic violence on academic performance was low. This implies that prevalence of domestic violence on academic performance was high with $69.6 \%$.

Research Question 2: What is the level of academic performance of secondary school in Itesiwaju Local Government Area, Oyo State?

Table 2

Percentage Analysis of Level of Academic Performance Secondary School in Itesiwaju Local Government Area, Oyo State

\begin{tabular}{lll}
\hline Level of Academic Performance & Frequency & Percentage (\%) \\
\hline High Level of Academic Performance & 782 & 61.09 \\
Low Level of Academic Performance & 498 & 38.91 \\
Total & 1280 & 100.0 \\
\hline
\end{tabular}

Table 2 presents the responses of the participants to items that sought information on the level of academic performance of secondary school in Itesiwaju Local Government Area, Oyo State. The results on Table 3 indicated that 554 representing (43.3\%) of secondary school students' academic performance was high, 235 representing (18.4\%) of secondary school students' academic performance was average, 491 representing (38.3\%) of secondary school students' academic performance was low. This implies that secondary school students' academic performance was high with $43.3 \%$.

\section{Hypothesis Testing}

Hypothesis One: There is no significant influence of domestic violence on Secondary School Students academic performance in Itesiwaju Local Government Area, Oyo State.

Table 3

Chi-square $\left(\chi^{2}\right)$ Analysis Showing Influence of Domestic Violence on Secondary School Students Academic Performance in Itesiwaju Local Government Area, Oyo State.

\begin{tabular}{|c|c|c|c|c|c|c|c|c|}
\hline \multirow[t]{2}{*}{ Source } & \multicolumn{3}{|c|}{ Prevalence } & \multirow[t]{2}{*}{ Total } & \multirow[t]{2}{*}{ df } & \multirow{2}{*}{$\begin{array}{l}\text { Cal. } X^{2}- \\
\text { value }\end{array}$} & \multirow{2}{*}{$\begin{array}{l}\text { Cal.Sig.(2- } \\
\text { sided) }\end{array}$} & \multirow[t]{2}{*}{ Decision } \\
\hline & & High & Low & & & & & \\
\hline \multirow[t]{3}{*}{ Domestic Violence } & Observed & 892 & 388 & 1280 & & & & \\
\hline & Expected & 903.4 & 376.6 & 1280.0 & & & & \\
\hline & & & & & & & & $\mathrm{H}_{01}$ \\
\hline Academic Performance & Observed & 782 & 498 & 1280 & 2 & 12.69 & 0.00 & Rejected \\
\hline
\end{tabular}

NB: $\rho<0.05$ 
Table 3 shows that the calculated $\chi^{2}$-value of 12.69 is greater than the critical $\chi^{2}$-value of 5.99 , with a corresponding p-value of 0.00 , which is less than the significant value of 0.05 . This indicated that a significant influence exists in the respondents' prevalence of domestic violence on academic performance; hence, the hypothesis was rejected.

\section{DISCUSSION}

The findings of this study revealed that the level of domestic violence on girl-child among secondary school students in Itesiwaju Local Government Area, Oyo State was high. Another finding revealed that secondary school students' academic performance was high with $61.09 \%$ of the participants. This finding is in consonance with that of Udo (2008) who reported that level of students' achievement in Agricultural Science in Oron Educational Zone was high. This was due to the fact that the girl-child were determined to be successful in other to become a person of influence in the society due to their experience in relation to domestic violence.

\section{CONCLUSION}

The findings of this study revealed that the level of domestic violence on girl-child among secondary school students in Itesiwaju Local Government Area, Oyo State was high. Another finding revealed that secondary school students' academic performance was high. Findings further revealed that there was a significant influence of domestic violence on girl-child academic performance in secondary schools in Itesiwaju Local Government Area, Oyo State.

\section{RECOMMENDATIONS}

The following recommendations were made based on the findings of the study.

There should be guidance and counselling therapy sessions in both school and community level. This will educate sensitise and rehabilitate each and every individual in the society. This would also help students to cope with the trauma associated with the violence. The helping professionals should take responsibility of reporting the suspected abuse to the child protection agency or police; this would reduce the rate of violence since law will be applied effectively to apprehend offenders typically counsellors and school personnel should be required to report and be granted immunity from liability because they are presumed to be acting in good faith.

The government has also enacted laws but its efforts of implementing them bear no fruits, therefore strict laws should be formulated to protect the children. Communities, churches, mosques schools and the government should take the responsibility of minimizing domestic violence and provide security for the young ones in particular and the community as a whole. Offices should be erected in communities where one is able to report to in case of such incidences, they should be in strategic positions and easy to access in order to stem out the vice. Sociologist of education should keep abreast of the indicators of maltreatment in schools in order to help victims of domestic violence.

\section{REFERENCES}

Alabi, O. P. \& Oni, I. O. (2017). Impact of domestic violence on academic performance of secondary school Students in Owo Local Government, Nigeria. Afro Asian J of Social Sciences, 111(11), 47-59.

Dlamini, S. L., \& Makondo, D. (2017). Effects of child abuse on the academic performance of primary school learners in the Manzini Region, Swaziland. World Journal of Education, 7(5), 58 - 65.

Donna, M., William, R., \& Clifford, J. (2012). Understanding child behaviour disorders. Holt. Rinchart and Winston. 
Dutton, M. A. (2014). Post-traumatic therapy with domestic violence survivors: Handbook of Posttraumatic therapy. Green wood Press.

Easteal, P. (2014). Violence against women in the home. Family Matters, 37, 25-27.

Federico, P. L., \& Schwartz, D. (2013). Sociology. Addison-Wesley.

Freedman, D., Thornton, A., Camburn, D., Alwin, D., \& Young-DeMarco, L. (2017). The life history calendar: A technique for collecting retrospective data. Sociological Methodology, 18, 37-68.

Giddens, A. (2012). Sociology. New York: Polity Press.

Gracier, E., \& Herrero, J. (2007). Perceived neighbourhood social disorder and attitudes toward reporting domestic violence against women. Journal of Interpersonal Violence, 22, 737-752.

Graham, S. (2014). Preventing domestic violence. University of Michigan.

Gwirayi, P. (2012). Child sexual abuse among urban secondary school pupils: Impact of family characteristics and family structure. Int. Review of Social Sciences and Humanities, 3(1), 36-50.

Jones, A. (2014). Next time, she 'll be dead. Battering and how to stop it. Beacons Press.

Kanchiputu, P. G., \& Mwale, M. (2016). Effect of domestic violence on children's education: The case study of Mpemba, in Blantyre District (Malawi). Psychol Abnorm, 5, 152.

Meichenbaum, D. (2014). Practical therapist manual for assessing and treating adults with posttraumatic stress disorder. Ontario, Canada: Institute Press.

Mitchell, A. (2012). Violence in the family. Wayland Publishers.

Njeru, P. G, Katiba, D., \& Mugambi, M. M. (2017). Effects of the domestic violence on academic performance of pupils in Magumoni Division, Tharaka Mithi county. Devi Country Stu., 7(9), 60-65

Njoroge, D. N. (2014). Effects of domestic violence on academic performance of public secondary schools: A case of Muguga Location, Kiambu County (Unpublished master thesis). University of Nairobi.

Population Report. (2017). Ending violence against women. Volume XXVII. Number 4. Maryland.

Schaefer, R., \& Lamm, R. (2013). Sociology. McGraw-Hill.

Sternberg, K.., Lamb, M., Guterman, E., \& Abbott, C. (2005). Effects of early and later family violence on children's behavior problems and depression: A longitudinal, multi-informant perspective. Journal of Child Abuse \& Neglect, 30, 283-306.

Storm, K. (2016). Helping a woman in crisis. A Handbook for people Helpers. Zonderran.

Straus, M., \& Gelles, R. (2010). Physical violence in American families. N.J: Transaction Publishers.

Sutherland, M. (2017). Gender equity in success at school. J. of Int Review on Education, 45,431-443.

Taylor, J. (2012). Sexual and domestic violence. Help Recovery and Action in Zimbabwe. Union Avenue, Harare - Zimbabwe.

Tolman, R. (2001) Domestic violence in the lives of women receiving welfare; Economic well-being. Violence against Women, 7, $141-158$.

Tuckman, B. (2014). Conducting educational research. Orlando. Florida: Harcourt Brace Jovanovich. 